\title{
Impact of climate change on a landslide in South East France, simulated using different G C M scenarios and downscaling methods for local precipitation
}

\author{
J elle Buma ${ }^{1, *}$, M artin Dehn² \\ ${ }^{1}$ Department of Physical G eography, Utrecht University, PO Box 80115, 3508TC Utrecht, The Netherlands \\ ${ }^{2}$ Department of G eography, University of Bonn, M eckenheimer Allee 166, 53115 Bonn, G ermany
}

\begin{abstract}
The aim of this paper is to assess the influence of different climate scenarios on scenarios for the impact variable 'Iandslide activity'. For this purpose, a site-specific model was used, relating the activity of a landslide in South East France to climate. Landslide activity was reconstructed from tree ring data. Hydrological field data indicated that the controlling climatic variable is net precipitation (precipitation minus evapotranspiration). However, this variable and hence the impact model could not explain all of the variations in landslide activity. The landslide model was fed with 1 temperature and several precipitation scenarios obtained by applying 3 different methods for downscaling 3 different general circulation model (GCM) simulations of the large-scale climate. The skill of the downscaling methods in reproducing the historical local precipitation was either limited or trivial, but fair enough to justify further application. The resulting scenarios for landslide activity were quite similar, with the exception of 2 specific combinations of GCM and downscaling method. Furthermore, short-term climatic variation, plausibly represented in one of the downscaling methods as a random noise component, caused additional variation in the resulting scenarios. The amount of variation in the climate scenarios is of the same order of magnitude as that in the landslide model. The general conclusion is not to focus on calibrating impact models while using only 1 climate scenario, but to assess the overall uncertainty of the impact scenario by considering different parameter settings of the impact model as well as different climate scenarios, as was done in the present study.
\end{abstract}

KEY WORDS: Landslide activity · Hydrology · Climate change impact · Downscaling · GCMs

\section{INTRODUCTION}

General circulation models (GCMs) are capable of providing plausible, physically based scenarios of future climate on a large scale (Trenberth 1997), but less so on a regional scale (Grotch \& McCracken 1991). This is mainly due to the low spatial resolution of most GCMs (currently around $250 \times 250 \mathrm{~km}$ ), and coarsescale model parameterizations (Giorgi \& M earns 1991). For climate change impact studies, regional- or localscale climate scenarios are needed. A common way to

*Present address: Engineering Department, Rotterdam Public Works, PO Box 6633, 3002A P Rotterdam, The Netherlands. E-mail: j.buma@gw.rotterdam.nl derive these is to interpolate large-scale, gridded GCM output to the desired locality, and to append the difference between the future ('target') and present-day ('reference') periods of this interpolated scenario to the observational record of the locality. This approach may result in misleading impact scenarios, because it does not take into account the spatial variability and nonlinearity of regional climate changes in response to mesoscale forcings, such as orography, which are not resolved by current GCM s (Wigley et al. 1990, Giorgi $\&$ M earns 1991). Especially direct interpolation of precipitation has many shortcomings, such as inadequate parameterizations of the process in the GCMs and the averaging of precipitation over the entire GCM gridbox (Airey \& Hulme 1995). 
Statistical downscaling methods are a potential alternative. In these approaches, the local climate is statistically related to large-scale climate variables which are simulated more reliably by GCMs (Hewitson \& Crane 1996, Zorita \& von Storch 1998). Thus, more plausible local climate change scenarios may be expected from statistical downscaling, albeit under one important condition: the large-scale climate simulated by the GCM must be precedented in the historical record; otherwise the statistical relations lose stationarity and hence validity. Furthermore, it must be realised that under large-scale climatic conditions similar to the present but occurring in a higher-temperature future climate enhanced evaporation from the oceans may still result in changing precipitation amounts on the continents. Other restrictions to statistical downscaling, from the impact community point of view, are (1) the limited portion of local climate variability that is explained by the large-scale situation, and (2) the sometimes complicated statistical procedures which may dissuade impact researchers.

In this study, the influence of different GCMs and downscaling methods on the simulated impact of climate change on a landslide in South East France is investigated. Three GCMs and 3 downscaling methods were considered. In the following, we first describe the landslide under study, its relation to climate, and the model to simulate this relation; then the GCM experiments and downscaling methods are described, followed by the use of the downscaling methods to reproduce the observed local climate. Section 5 deals with the scenarios of future climate, while Section 6 addresses their application to the impact model, resulting in scenarios of future landslide activity. The conclusions of this study are summarised in Section 7.

\section{THE LANDSLIDE}

\subsection{Observations}

Landslides are a major source of human and economic loss in mountain regions throughout the world. Landslides can be defined as 'downward and outward movements of slope forming materials under the influence of gravity' (Varnes 1978). Earthquakes, undercutting of slopes by rivers or seas, and excessive precipitation are common landslide triggers (Crozier 1986). In the latter case, excessive infiltration and percolation into the slope increase the pore pressure. Higher pore pressures decrease the intergranular (resisting) forces along an existing or potential slide surface, increasing the probability of slope instability (e.g. Craig 1987 and references therein).
The Boisivre landslide is situated on the eastern slope of the Riou Bourdoux valley, in the basin of Barcelonnette in the French Alps (Fig. 1). The nearest weather station, Barcelonnette 'Le Verger' is about $4 \mathrm{~km}$ to the southeast. The observations of the landslide described below were collected and first presented by Caris \& van Asch (1991) and Mulder (1991). The landslide has a length of about $170 \mathrm{~m}$. The slide surface runs parallel to the ground surface, at a depth of about $7 \mathrm{~m}$ below the ground surface. The geology of the landslide may be described as follows: unweathered marl bedrock (depth below ground surface $>7 \mathrm{~m}$, very low permeability); weathered marl (depth below ground surface about 1.5 to $7 \mathrm{~m}$, low permeability); and glacial till (ground surface to about $1.5 \mathrm{~m}$ below, high permeability).

The decrease in permeability probably governs the reactivation mechanism of the landslide (Caris \& van Asch 1991). The direct trigger is the build-up of a critical pore pressure at the slide surface as a result of the percolation of water through the weathered marl. Field observations revealed that rain water infiltrates into cracks and macropores in the till layer. In summer this water is available to the vegetation for transpiration, but in winter it is allowed to infiltrate further into the weathered marl and onto the slide surface. Therefore, percolation will mainly take place during the winter half-year, or, more generally, after periods of high net precipitation (net precipitation $=$ percolation $=$ precipi tation - evapotranspiration). The time scale of triggering is probably several months rather than a single rainstorm, which will generate too small amounts of percolation to critically raise the groundwater table (Caris \& van Asch 1991).

\subsection{The model}

Buma (1998) tried to quantify the relation between landslide reactivation and climate by comparing the time series of net precipitation (as defined above) with landslide reactivation data. The latter were derived from tree ring analyses, assuming that landsliding causes trees to slant, resulting in tree ring eccentricities (Braam et al. 1987). Tree ring data from 1956 to 1980 were used to reconstruct the landslide reactivation record. The associated temporal resolution is yearly. A time series of net precipitation covering the same period was calculated with a simple water balance model for the till. The model requires monthly precipitation and temperature data, and soil moisture retention curves of the till. To meet the desired climatic time scale outlined earlier, the net precipitation time series was aggregated to 3 mo running sums. For details of the model see Buma (1998). 
Fig. 2 shows the resulting climatic and landslide reactivation time series. The square symbols are based on the tree ring analyses. The diamond symbols are based on the climatic data exceeding the threshold. Both symbols series should match. The threshold shown is $270 \mathrm{~mm}$. This means that whenever the amount of net precipitation over 3 mo exceeds $270 \mathrm{~mm}$,

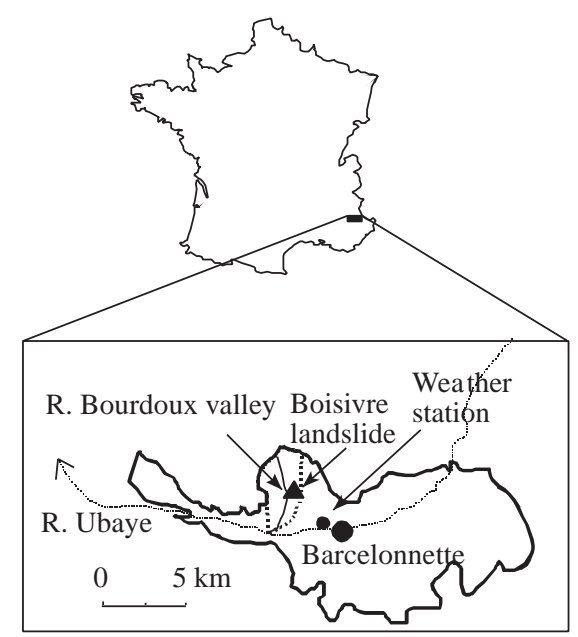

Fig. 1. Regional setting of the Boisivre landslide in the Barcelonnette basin (bold line), France a landslide reactivation should occur, according to the model. The threshold only allows events and 'nonevents' to be discriminated; the model is too coarse for event magnitudes to be assessed. The match is not perfect, because in the dry years 1974-1975 a reactivation occurred. Furthermore, the duration of landslide reactivation is systematically overestimated by the model.

The frequency of landslide reactivation $(\phi)$ was subsequently calculated. The annual maxima of the climatic time series (during the period 1960 to 1989) were identified and ranked in ascending order (30 values). The return interval of each annual maximum is related to this ranking according to the theory of statistics of extreme values formulated by Gumbel (1958). A linear regression relating these 2 variables provided a significant fit with an $r^{2}$ of about 0.95. Substituting the threshold value $(270 \mathrm{~mm})$ in the regression provided a $\phi$ of $0.27 \mathrm{yr}^{-1}$ (landslide reactivation about once every $4 \mathrm{yr})$.

Several factors complicate the relation shown in Fig. 2. First, the tree ring record may be contaminated by false rings or the absence of rings (as a result of abnormal weather conditions during the growing season) or counting errors. Second, tree slanting may have other causes such as wind action or disease. Third, the model does not take into account the time it takes the

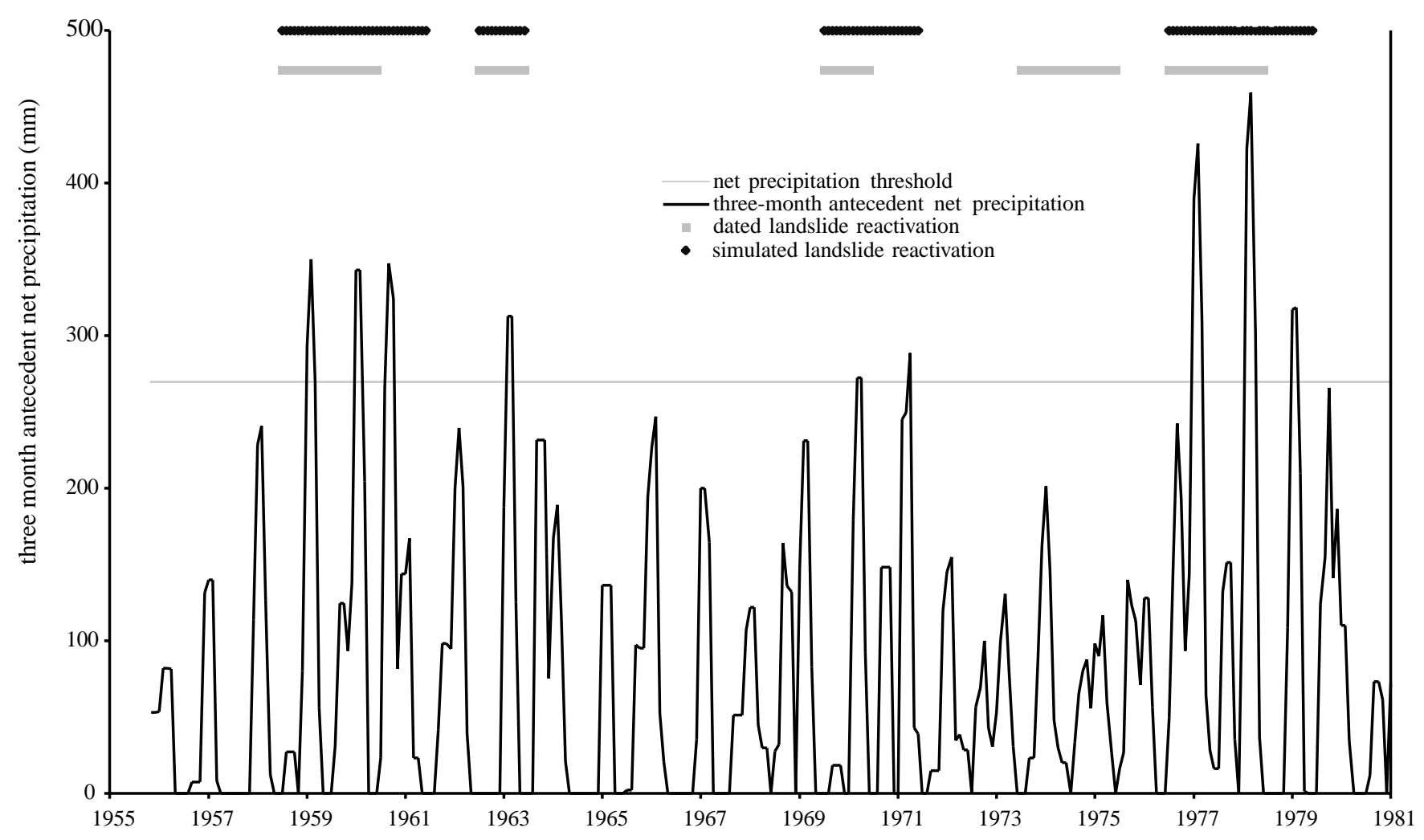

Fig. 2. Three-month sums of net precipitation compared to landslide reactivation, derived from tree ring analyses 
water to percolate through the weathered marl. This time lag may also be variable in time; more water may be needed to raise the groundwater table, as a result of drainage in a preceding period of relative drought. Finally, landslide reactivation may be more likely to occur after long periods of slope stability in which the build-up of shear stress is allowed. Conversely, reactivation may cease as a result of feedback mechanisms once the shear stress is released. This may explain why the duration of reactivation is in general overestimated.

It may be concluded that the presented model for landslide reactivation as a function of climatic parameters still carries too many uncertainties for a successful application to climate change impact assessment. However, the focus of this paper is to determine the influences of different GCMs and downscaling methods on simulated climate change impacts on landsliding. For this purpose even a theoretical model relating climate to landslide activity would have been suitable. Therefore, the landslide model is considered good enough for the scenario study.

\section{GCM EXPERIMENTS AND DOWNSCALING METHODS}

3.1. GCM experiments. The characteristics of the 3 GCM experiments used in this study are listed in Table 1.

3.2. Downscaling methods. In the following, the term 'reference period' indicates the historical period used as a validation of the downscaling procedures.
On the other hand, 'control period' refers to the period over which GCM experiments were forced with observed and reconstructed greenhouse gas concentrations (1860 to 1990).

3.2.1. Direct GCM interpolation: Direct GCM interpolation comprises 2 stages: (1) Interpolation stageinterpolation of gridded GCM data to the desired location. (2) Transformation stage-the mean difference between the reference climate and a target climate situation, as estimated from the interpolated GCM time series, is appended to the historical time series. The target period can be any period of the GCM scenario other than the reference period. The reference period should coincide with the period of observation.

The transformation of a temperature time series for a single locality proceeds as follows:

$$
\mathrm{T}_{\mathrm{TAR}}(\mathrm{y}, \mathrm{m})=\mathrm{T}_{\mathrm{OBS}}(\mathrm{y}, \mathrm{m})+\left[\mathrm{T}_{\mathrm{GCM}, \mathrm{TAR}}(\mathrm{m})-\mathrm{T}_{\mathrm{GCM}, \mathrm{REF}}(\mathrm{m})\right]
$$

where $\operatorname{TTAR}_{\operatorname{TA}}(y, m)=$ temperature in year $y$ and month $m$ in the target climate period; $\mathrm{T}_{\mathrm{OBS}}(\mathrm{y}, \mathrm{m})=$ temperature in year $y$ and month $\mathrm{m}$ of the historical time series; and $T_{G C M, T A R}(m)-T_{G C M, R E F}(m)=$ temperature difference between target and reference period estimated by the GCM for month $m$.

For precipitation $(\mathrm{P})$, the procedure is slightly different:

$$
\mathrm{R}_{\mathrm{TAR}}(\mathrm{y}, \mathrm{m})=\mathrm{R}_{\mathrm{OBS}}(\mathrm{y}, \mathrm{m}) \cdot\left[\mathrm{R}_{\mathrm{GCM}, \mathrm{TAR}}(\mathrm{m}) / \mathrm{R}_{\mathrm{GCM}, \mathrm{REF}}(\mathrm{m})\right]
$$

For textual convenience, climate scenarios derived by direct interpolation will be referred to as 'direct scenarios'.

\begin{tabular}{|c|c|c|c|}
\hline & ECHAM 4-OPYC3 & HadCM 2-GG & HadCM 2-GS \\
\hline Institute & $\begin{array}{l}\text { Max-Planck-Institut für } \\
\text { M eteorologie, Hamburg }\end{array}$ & Hadley Centre, UK & Hadley Centre, UK \\
\hline Reported in & Roeckner et al. (1996) & J ohns et al. (1997) & J ohns et al. (1997) \\
\hline Type & $\begin{array}{l}\text { Transient, coupled } \\
\text { ocean-atmosphere } \\
\text { GCM experiment }\end{array}$ & $\begin{array}{l}\text { Transient, coupled } \\
\text { ocean-atmosphere } \\
\text { GCM experiment }\end{array}$ & $\begin{array}{l}\text { Transient, coupled } \\
\text { ocean-atmosphere } \\
\text { GCM experiment }\end{array}$ \\
\hline Spatial resolution & $2.8^{\circ} \times 2.8^{\circ}(\mathrm{T} 42)$ & $2.5^{\circ}$ (lat.) $\times 3.75^{\circ}$ (long.) & $2.5^{\circ}$ (lat.) $\times 3.75^{\circ}$ (long.) \\
\hline Control period & $1861-1990$ & 1860-1990 & 1860-1990 \\
\hline Scenario period & 1991-2099 & 1991-2099 & 1991-2099 \\
\hline Control period forced with & $\begin{array}{l}\text { Observed/reconstructed } \\
\text { greenhouse gas } \\
\text { concentrations }\end{array}$ & $\begin{array}{l}\text { Observed/reconstructed } \\
\text { greenhouse gas } \\
\text { concentrations }\end{array}$ & $\begin{array}{l}\text { Observed/reconstructed } \\
\text { greenhouse gas } \\
\text { concentrations }\end{array}$ \\
\hline Scenario period forced with & $\begin{array}{l}\text { IPCC IS92a emission scenario } \\
\text { (Houghton et al. 1992) }\end{array}$ & $\begin{array}{l}\text { IPCC IS92a emission scenario } \\
\text { (Houghton et al. 1992) }\end{array}$ & $\begin{array}{l}\text { IPCC IS92a emission scenario } \\
\text { (Houghton et al. 1992) }\end{array}$ \\
\hline Greenhouse gases considered & Greenhouse gases only & Greenhouse gases only & $\begin{array}{l}\text { Greenhouse gases and } \\
\text { sulphate aerosols }\end{array}$ \\
\hline Referred to in this paper as & ECHAM 4 & HCGG & HCGS \\
\hline
\end{tabular}

Table 1. Characteristics of the GCM experiments used in this study 
3.2.2. Downscaling based on multiple regression: Canonical correlation analysis is a linear regression between 2 space-time-dependent variables, each consisting of a number of time series measured at different locations. In the climatological application, the predictor variable is a large-scale variable $L$, the predictand variable a local-scale surface variable $R$ (Barnett \& Preisendorfer 1987, von Storch et al. 1993, von Storch \& Navarra 1995, Heyen et al. 1996). In the present study $\mathrm{R}$ consists of 1 station only, so the downscaling technique is instead a multiple regression. Prior to the regression, a data-reduction procedure is carried out by projecting the time series onto a few empirical orthogonal functions (EOFs; Heyen et al. 1996) which explain a major part of the total variance.

3.2.3. Downscaling based on nearest-neighbour analogs (analog-downscaling): The analog approach applied in this study is described in Zorita et al. (1995) and Cubasch et al. (1996). Given a large-scale climate situation, the approach finds the nearest analog of each GCM day in the observed large-scale climate record, and assigns the local climate belonging to this observational day to the GCM day. The large-scale climate situations are characterized by a vector $L\left(I_{1 \ldots n}\right)$, where each I represents a real or EOF time series of a large-scale climate variable. The GCM-simulated and observed large-scale climate situations are characterized by vectors $L(t)$ and $L^{\prime}(t)$ containing the spatial pattern of the large-scale climate on Day $t$. The nearest analog in the observational record $L^{\prime}(t)$ has the lowest Euclidian distance to the vector $\mathrm{L}(\mathrm{t})$ of the GCM day. The approach is validated on an independent, historical data set by comparing the local climate assigned by the analogs to the observations. The dimension of the vectors may be extended by including more largescale variables or by including antecedent local or large-scale conditions (Cubasch et al. 1996). Another refinement was presented by Brandsma \& Buishand (1997), who considered more than 1 'near neighbour' as analogs and applied a stochastic procedure to select 1 of them. In doing so, the (unexplained) variability, given a large-scale climate state, is taken into account.

\section{APPLICATION OF THE DOWNSCALING METHODS TO HISTORICAL BARCELONNETTE CLIM ATE}

\subsection{Procedures}

The performance of the 2 statistical downscaling methods in reproducing the observed Barcelonnette precipitation was tested by downscaling from the observed large-scale climate. Temperature was not downscaled with these methods; the temperature sce- narios presented in Section 5 were derived by direct GCM interpolation (average of several grid boxes). This was motivated by the fact that in general the correlation between local and large-scale values is better for temperature than for precipitation.

Observed temperature (1956 to 1994) and precipitation time series (1928 to 1994) of the weather station Barcelonnette 'Le Verger' were obtained from M étéofrance. A monthly time scale for downscaling is considered sufficient to capture the time scale of the climatic landslide triggering mechanism, as outlined in Section 2.

The multiple regression was performed with observed mean monthly North A tlantic sea level pressure (SLP) as the predictor variable and local monthly precipitation as predictand. We used re-analyses of SLP observations by the US National Center for Environmental Prediction (NCEP) interpolated to a $5^{\circ} \times 5^{\circ}$ grid (Trenberth \& Paolino 1980). The applied field over the period 1928 to 1994 includes 153 grid points covering the region $40^{\circ} \mathrm{W}-40^{\circ} \mathrm{E}, 30^{\circ}-70^{\circ} \mathrm{N}$. The first 4 EOFs of the SLP fields, al ways explaining $>80 \%$ of the variability, were retained for the regression. The regression models were built for each month separately over the period 1928 to 1994. The regressions were carried out with anomalies relative to the long-term means. All precipitation series were power-transformed prior to the regressions in order to obtain normally distributed variables. Validation of the multiple regression was done by means of a cross-validation procedure (M ichaelsen 1987).

The procedure for analog-downscaling applied in this study considered daily North Atlantic SLP of the current and the 2 preceding days. The analog was selected from 1 nearest neighbour only. The anomalies were projected on the first 5 EOFs of the SLP of the training period. To filter out seasonal influences, the procedure was carried out separately for the 4 seasons. The training period was 1928 to 1957, the validation period 1958 to 1991. The selection criteria for the number of retained EOFs was model performance. This was not rigorously tested, but on average the performance was better with 5 EOFs than using more or less patterns.

\subsection{Results}

\subsubsection{Downscaling with multiple regression}

Fair correlations between North Atlantic SLP and Barcelonnette precipitation could be found for October through April. The explained variance of the cross-validation between observed and downscaled precipitation time series ranged from 23 ( $M$ arch) to 
$52 \%$ (February). For May through September lower explained variances were found. Fig. 3 shows the explained variance of the cross-validation for all months.

The limited amount of variance in Barcelonnette precipitation explained by North Atlantic SLP causes a variability reduction in the downscaled precipitation series. This shortcoming was solved by adding a noise component to the downscaled series, as proposed by Zorita \& von Storch (1998). The noise may be physically interpreted as all of the climatic factors causing variability in Barcelonnette precipitation which are not captured by the multiple regression. These factors may be operating on a local scale, but large-scale atmospheric features may also be missed by the regression. In statistical terms the noise is represented by the residual (unexplained) variance of the regression model. Dehn \& Buma (1999) added the noise component by randomly resampling from the residuals of 1928 to 1994. This was allowed because the residuals of the multiple regression were not autocorrelated on a monthly scale. In the present study, 1000 values were randomly selected from the normally distributed, power-transformed 1928 to 1994 residuals. Each selected residual was added to the downscaled value. Subsequently their sum was back-transformed, resulting in 1000 realisations of downscaled monthly precipitation time series (1928 to 1994). Putting these time series into the landslide model provided $1000 \phi$ values with a median of $0.29 \mathrm{yr}^{-1}$, a $5 \%$ quantile of $0.18 \mathrm{yr}^{-1}$ and a $95 \%$ quantile of $0.42 \mathrm{yr}^{-1}$. This corresponds fairly well with the $\phi$ of $0.27 \mathrm{yr}^{-1}$ obtained with historical precipitation, but it also shows that $\phi$ is rather sensitive to variation not captured by the multiple regression.

\subsubsection{Analog-downscaling}

Fig. 3 also shows the explained variances of the analog-downscaling for all months. In the winter half-year, the explained variances of the analog technique are lower than those obtained with multiple regression, except for J anuary (32 vs $29 \%$ ). In the summer halfyear the opposite is the case, notably in September (20 vs $4 \%$ ). N ote that the procedures for validation are not identical for multiple regression and analog-downscaling. Furthermore, the absolute precipitation amounts are generally underestimated by the analogs (not shown). Overall, the skill of the analogs is somewhat lower than the skill of the multiple regression. However, the evaluation was restricted to mean precipitation, and variability on different frequencies was not taken into account. Furthermore, mean precipitation is by definition correct for the multiple regression, because observed means and noise are added to the anomalies at the end of the procedure. This type of calibration is not included in the analog technique. There may be several ways to improve the performance of the analog method, as outlined in Section 3.

It goes without saying that the landslide frequency obtained with the landslide model and analog-downscaled time series did not match the value of $0.27 \mathrm{yr}^{-1}$ obtained with the historical time series.

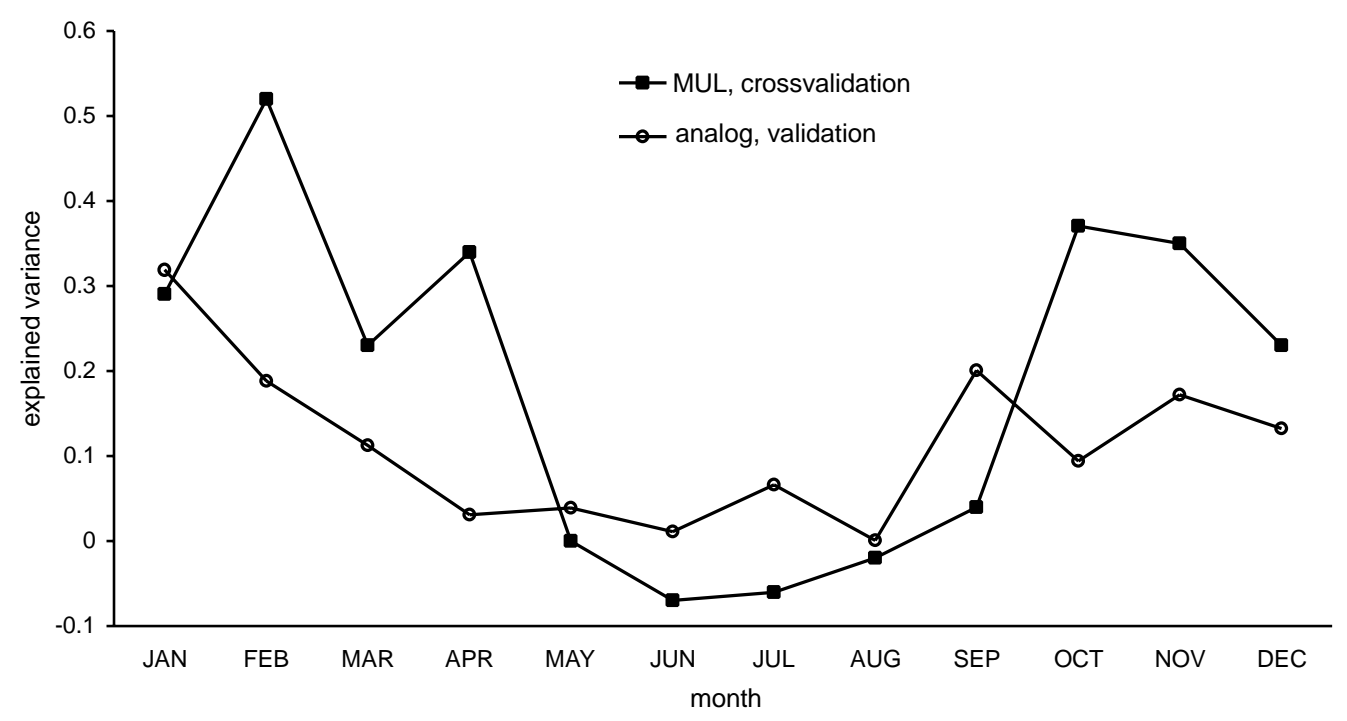

Fig. 3. Explained variances of downscaled local precipitation for the multiple regression, MUL (cross-validation of period 1928-1994) and the analog technique (validation period 1958-1991). See text for explanation 


\section{LOCAL CLIMATE SCENARIOS FOR BARCELON NETTE}

\subsection{Procedure}

\subsubsection{Direct GCM interpolation (temperature and precipitation)}

A direct interpolation from the 6 (HCGG/HCGS) or 16 (ECHAM 4) nearest GCM gridpoints was carried out to obtain precipitation and temperature scenarios for the Barcelonnette coordinates. Subsequently the average temperature and precipitation differences between the reference and target periods were calculated according to Eq. (1a,b). The reference period was 1960-1989, the target periods were 1870-1899, 1910-1939, 2020-2049, 2050-2079 and (Hadley GCM s only) 2070-2099.

\subsubsection{Downscaling with multiple regression (precipitation)}

The multiple regression models of October through April were applied to North Atlantic SLP simulated by the GCMs. In the absence of good correlations, precipitation for May through September was randomly selected from the normal, power-transformed distributions of the 1928 to 1994 observations, which were not mutually (auto)correlated. Therefore, the scenarios for summer (J une through August) obtained with multiple regression reflect the historical statistics. This is also partly the case with spring (March through May) and autumn (September through November).

\subsubsection{Analog-downscaling (precipitation)}

The nearest-neighbour analogs of the large-scale vectors $L$ of each day of the GCM scenarios were searched in the observational record. The corresponding precipitation was then assigned. Due to data provision problems of both climate modeling centers, the procedure was restricted to 2 GCMs (ECHAM 4 and HCGS) and different target periods: 1960-1989 and 2070-2099 for ECHAM 4; 1950-1979, 2020-2049 and 2070-2099 for HCGS.

\subsection{Local climate scenarios}

\subsubsection{Temperature scenarios}

The differences between directly interpolated GCM temperature and observations for the period 1956 to
1994 are shown in Fig. 4a; they are suspected to reflect altitude differences between Barcelonnette and the GCM grid boxes. Therefore, monthly correction terms were determined and applied as constant to the temperature scenario from 1860 to 2099, see also Eq. (1a). The corrected scenarios are shown in Fig. 4b. Steady upward trends are visible, while the tempering effect of sulphate aerosols is evident in the HCGS scenario. The magnitudes of temperature rise simulated by the 2 greenhouse-gas-only GCM s also differ markedly. This illustrates the disagreement of current-generation GCMs on the magnitudes of simulated temperature changes.

\subsubsection{Precipitation scenarios}

The precipitation scenarios are shown in Fig. 5a-d (per season). The discussion of the scenarios focuses on mean statistics. Extreme statistics, such as for example $90 \%$ quantiles of seasonal precipitation, are more important to landslide activity. The trends of these statistics are similar to the trends of the means (not shown). The discussion focuses on 2 main aspects: (1) The correspondence with the observations in the reference period 1960 to 1989 (1950 to 1979 for HCGS and analog only). (2) The significance of the simulated future trends in precipitation is indicated by the difference between future (1991 to 2099) and control (1860 to 1990) periods, as opposed to the difference occurring within the control period. If the latter is equal to or larger than the former, the simulated future trends have little meaning. This difference is evaluated only qualitatively in this paper.

5.2.2.1. Direct GCM interpolation. The directly interpolated precipitation of the target period 1960 to 1989 is by definition identical to the observed precipitation for this period, since $R_{G C M, T A R}(m)=$ $\mathrm{R}_{\mathrm{GCM}, \mathrm{REF}}(\mathrm{m})$. The observed mean precipitation for 1960 to 1989 can be found in parentheses in the DIR columns of Table 2.

Distinct trends are simulated in winter (upward in all 3 scenarios) and in summer (downward in ECHAM 4 and HCGG). In autumn and spring, only HCGG shows distinct trends (downward and upward, respectively).

5.2.2.2. Downscaling with multiple regression. Mean scenario precipitation in the reference period is within $5 \%$ of the observed values, except for winter precipitation in both Hadley Centre scenarios. The good fit is partly trivial, because the use of anomalies in the regression filters out absolute biases between GCM simulated and historical large-scale climate. It mainly indicates that the GCM s reproduce the magnitudes of the anomaly fields of North Atlantic large-scale climate well. 
a

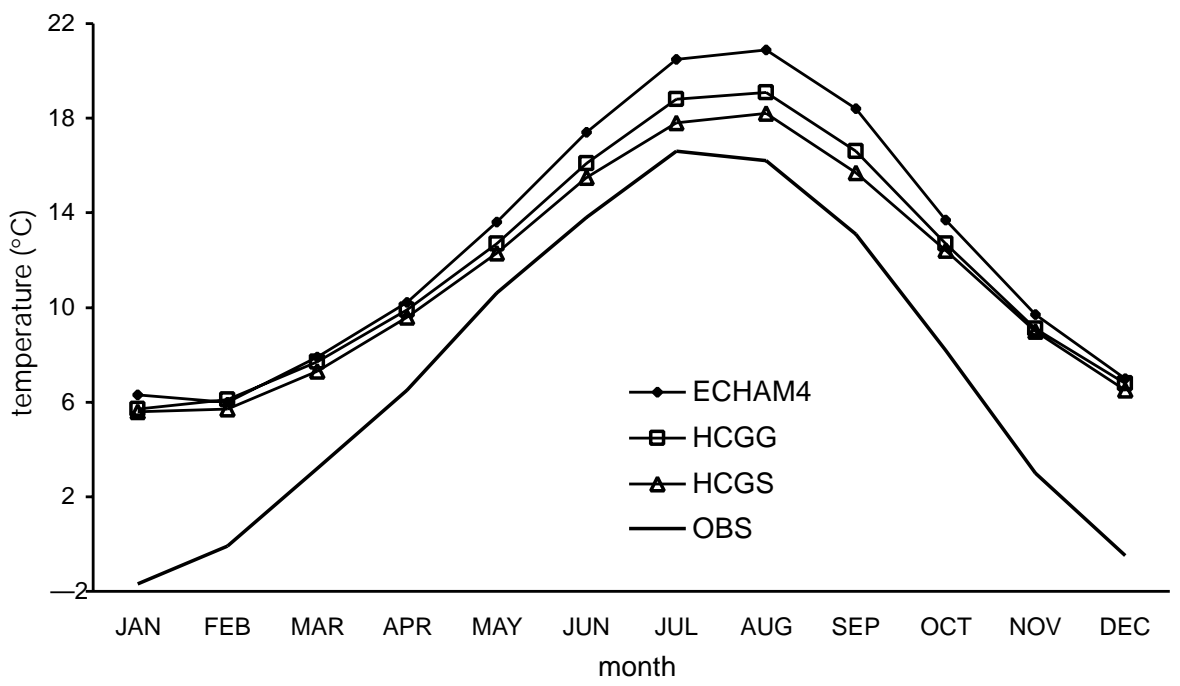

b

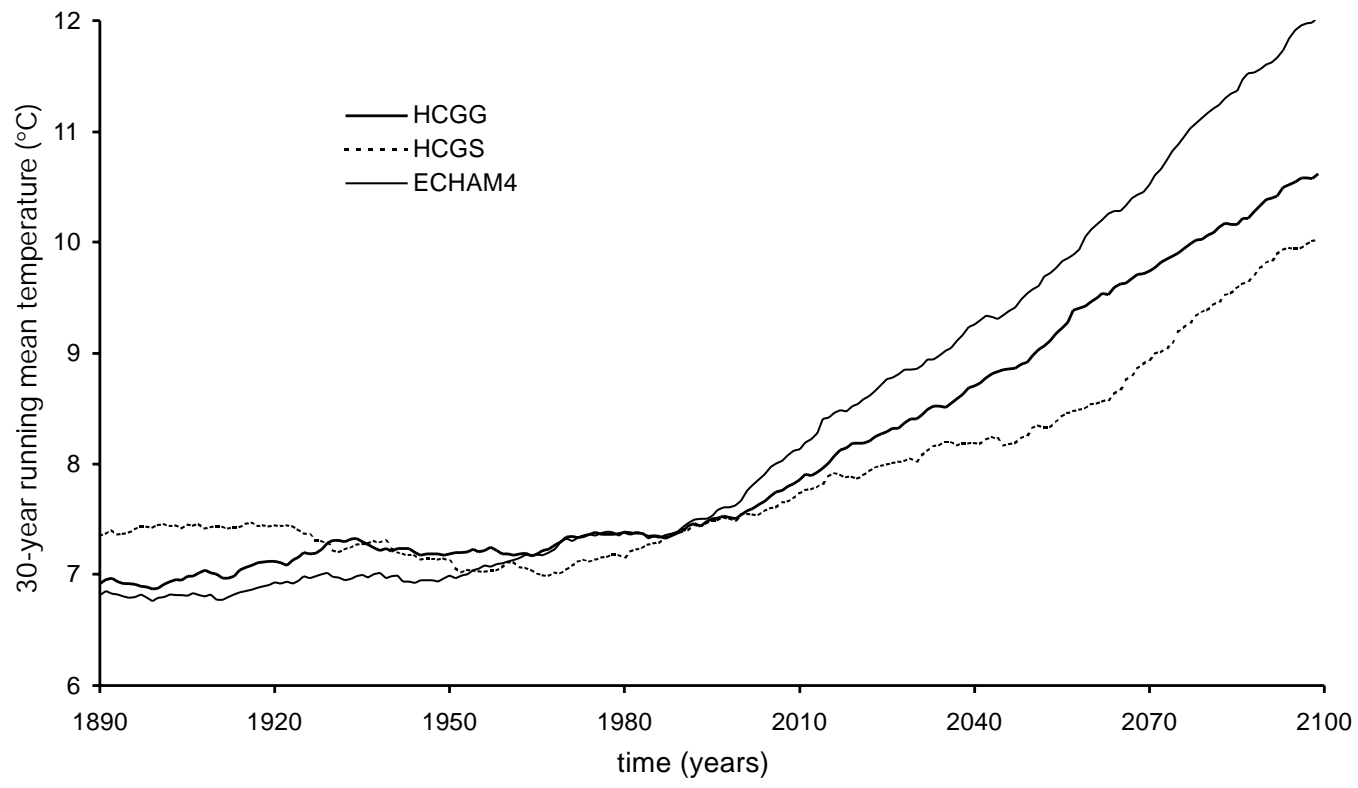

Fig. 4. (a) M ean annual cycle of air temperature in Barcelonnette, 1956-1994, from observations (OBS) and directly interpolated from 3 GCM experiments. (b) Temperature scenarios for Barcelonnette 'Le Verger', obtained by direct interpolation and transformation from 3 GCM experiments

Distinct trends are simulated in autumn (downward in ECHAM 4, to a lesser extent in HCGG) and in winter (upward in HCGG and HCGS). In spring, ECHAM 4 and HCGG both show distinct trends, but interestingly their directions are opposite (downward in ECHAM 4 and upward in HCGG).

5.2.2.3. Analog-downscaling. In both scenarios, the observations are underestimated in all seasons. Given the underestimation introduced by downscaling, the observed large-scale climate (see Section 4.3.2), it may be concluded that the underestimation is caused by the downscaling method rather than by a bias in the
GCMs. The poor correspondence makes the question of whether or not the simulated trends are significant irrelevant.

5.2.2.4. Comparison of the scenarios. The difference between analog on the one hand and multiple regression and direct interpolation on the other hand is obvious; the cause of this was al ready discussed in Section 4. As for the comparison between multiple regression and direct interpolation: from Fig. $5 \mathrm{~b}$ it appears that in the winter season the absolute precipitation amounts are determined more by the downscaling method than by the GCM. This is not the case in the other seasons. In gen- 
a

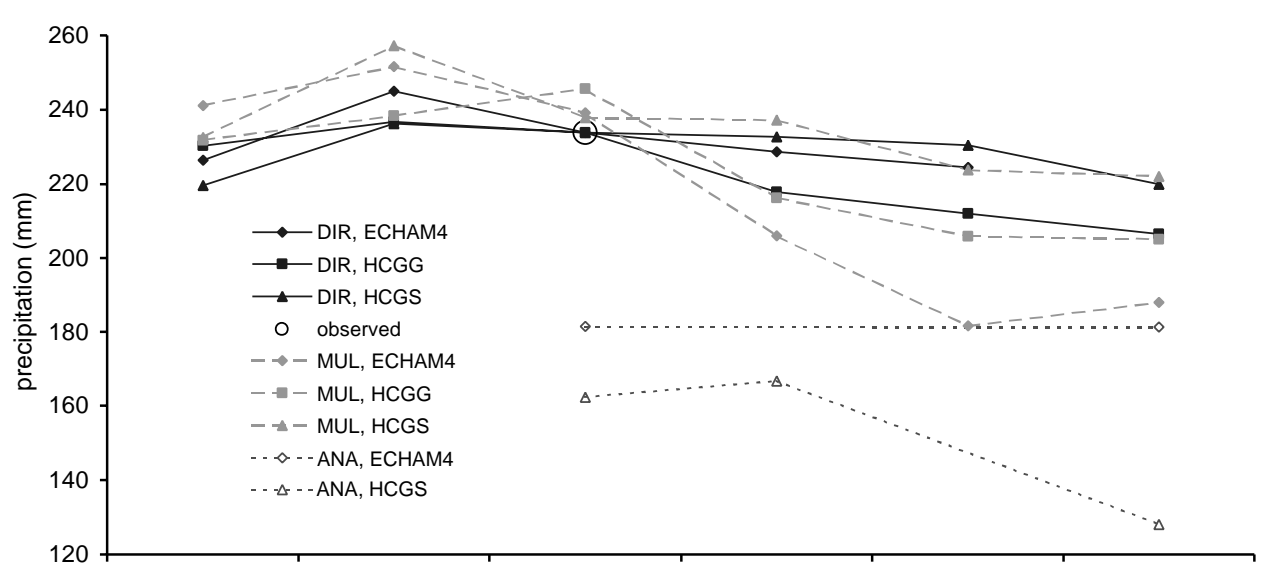

b

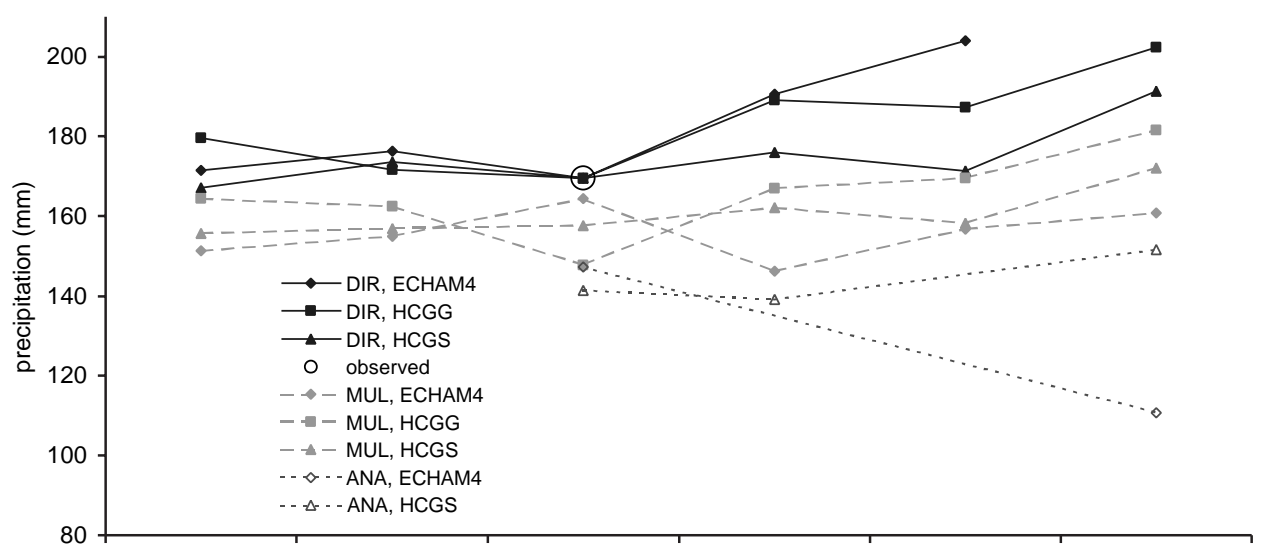

C

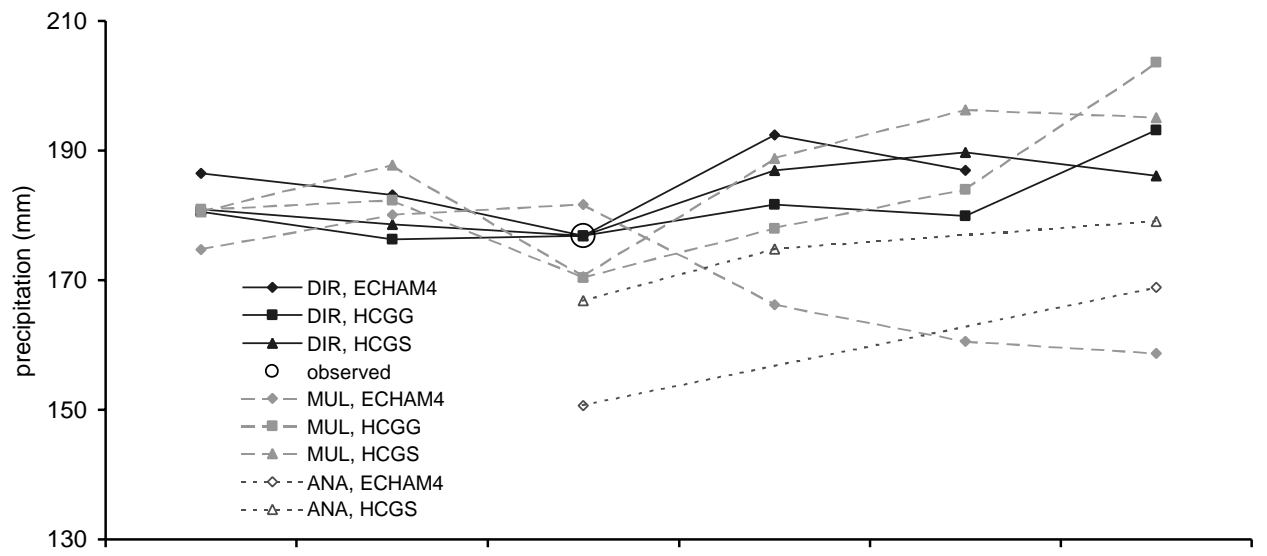

d

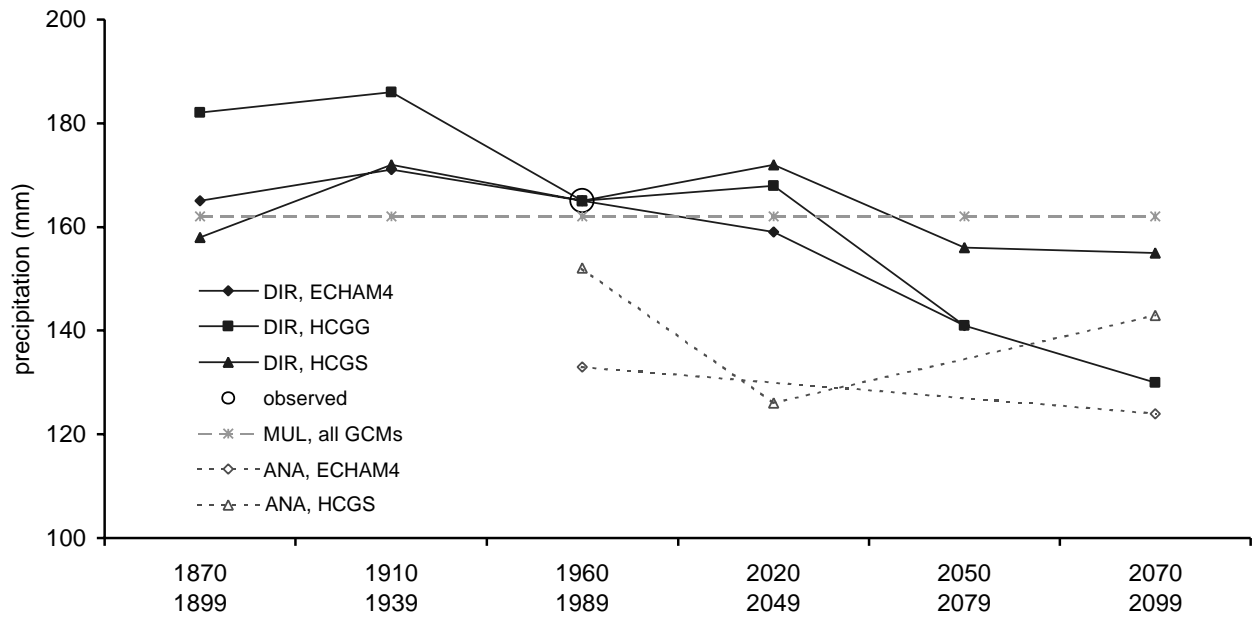

Fig. 5. Scenarios for mean monthly precipitation, obtained with different GCMs and downscaling methods. (a) Autumn (SON); (b) winter (DJ F); (c) spring (MAM); (d) summer (J J A). Note that the reference period of analog-downscaling with HCGS, 19501979, for convenience is plotted at the position of 1960-1989. DIR $=$ direct interpolation/transformation, MUL $=$ multiple regres- 
Table 2. Scenarios of mean seasonal precipitation (in $\mathrm{mm}$ ). The values in parentheses are trivial because they are entirely derived from observations (see text for further explanation). DIR = direct interpolation/transformation, MUL = multiple regression, ANA = analog-downscaling

\begin{tabular}{|c|c|c|c|c|c|c|c|c|c|c|c|c|}
\hline \multirow[t]{2}{*}{ Period } & \multicolumn{3}{|c|}{ Autumn } & \multicolumn{3}{|c|}{ Winter } & \multicolumn{3}{|c|}{ Spring } & \multicolumn{3}{|c|}{ Summer } \\
\hline & DIR & MUL & ANA & DIR & MUL & ANA & DIR & MUL & ANA & DIR & MUL & ANA \\
\hline \multicolumn{13}{|l|}{ ECHAM } \\
\hline 1870-1899 & 226 & 241 & - & 172 & 151 & - & 187 & 175 & - & 165 & (162) & - \\
\hline 1910-1939 & 245 & 252 & - & 176 & 155 & - & 183 & 180 & - & 171 & (162) & - \\
\hline 1960-1989 & (234) & 239 & 181 & (170) & 164 & 147 & (177) & 182 & 151 & (165) & (162) & 133 \\
\hline $2020-2049$ & 229 & 206 & - & 191 & 146 & - & 192 & 166 & - & 159 & (163) & - \\
\hline $2050-2079$ & 224 & 182 & - & 204 & 157 & - & 187 & 161 & - & 141 & (162) & - \\
\hline 2070-2099 & - & 188 & 181 & - & 161 & 111 & - & 159 & 169 & - & (162) & 124 \\
\hline \multicolumn{13}{|l|}{ HCGG } \\
\hline 1870-1899 & 230 & 232 & - & 180 & 164 & - & 181 & 181 & & 182 & (163) & - \\
\hline 1910-1939 & 237 & 238 & - & 172 & 163 & - & 176 & 182 & & 186 & (162) & - \\
\hline 1960-1989 & (234) & 246 & - & (170) & 148 & - & (177) & 170 & - & (165) & (163) & - \\
\hline 2020-2049 & 218 & 216 & - & 189 & 167 & - & 182 & 178 & - & 168 & (162) & - \\
\hline 2050-2079 & 212 & 206 & - & 187 & 170 & - & 180 & 184 & - & 141 & (163) & - \\
\hline 2070-2099 & 207 & 205 & - & 202 & 182 & - & 193 & 204 & - & 130 & (162) & - \\
\hline \multicolumn{13}{|l|}{ HCGS } \\
\hline 1870-1899 & 220 & 233 & - & 167 & 156 & - & 181 & 181 & - & 158 & $(162)$ & - \\
\hline 1910-1939 & 236 & 257 & - & 174 & 157 & - & 179 & 188 & - & 172 & $(162)$ & - \\
\hline 1950-1979 & - & - & 162 & - & - & 141 & - & - & 167 & - & - & 152 \\
\hline 1960-1989 & (234) & 238 & - & (170) & 158 & - & (177) & 171 & - & (165) & $(162)$ & - \\
\hline 2020-2049 & 233 & 237 & 167 & 176 & 162 & 139 & 187 & 189 & 175 & 172 & (162) & 126 \\
\hline 2050-2079 & 230 & 224 & - & 171 & 158 & - & 190 & 196 & - & 156 & (162) & - \\
\hline $2070-20$ & 220 & 222 & 128 & 191 & 172 & 152 & 186 & 195 & 179 & 155 & (162) & 143 \\
\hline
\end{tabular}

eral, precipitation increases in winter and spring, and decreases in summer and autumn. The multiple-regression-downscaled ECHAM 4 scenario is the most divergent, notably in spring, for which a precipitation decrease is simulated. The changes in HCGS are the least.

\section{SCENARIOS FOR LANDSLIDE REACTIVATION}

\subsection{Procedure}

The direct precipitation and temperature scenarios were used as input for the landslide model without further processing. Five target periods were selected, as in Fig. 5a-d: 1870-1899, 1910-1939, 2020-2049, 2050-2079 and 2070-2099. Again, the simulation of the 'observed' frequency of Iandslide reactivation $\phi$ in the reference period is trivial (see Section 5.1.2).

In the case of multiple regression, $\phi$ was calculated for target periods shifted at $10 \mathrm{yr}$ steps over the entire scenario period (1870-1899, 1880-1909, ..., 2070-2099). The 1000 regressed precipitation scenarios (see Section 4.2.2) resulted in $1000 \phi$ values. For each target period, the 10, 50 and $90 \%$ quantiles of these were calculated. The latter are shown to provide an indication of the variation in simulated impacts occurring within one combination of GCM and downscaling method.
The procedure for analog-downscaling is identical to that of the direct method. $\phi$ was calculated for the target periods given in Section 5.1.3.

\subsection{Results and discussion}

The scenarios of the frequency of $\phi$ generally follow the mean precipitation scenarios. The results are shown in Fig. 6.

\subsubsection{Direct GCM interpolation}

Distinct trends in $\phi$ were simulated in none of the GCMs. Apparently, decreased summer precipitation and increased evapotranspiration are cancelled out by increased winter and spring precipitation.

\subsubsection{Downscaling with multiple regression}

A distinct downward trend is simulated in ECHAM 4. In HCGG a weaker downward trend is simulated. The stronger trend in ECHAM 4 is not surprising, given the strong precipitation decreases in spring and autumn. In HCGS, the slight increases in precipitation are cancelled out by increased evapotranspiration. 




Fig. 6. Scenarios for the frequency of Iandslide reactivation ( $\phi)$ obtained with different GCMs and downscaling methods. DIR $=$ direct interpolation/transformation, $\mathrm{MUL}=$ multiple regression, $\mathrm{ANA}=$ analog-downscaling



Fig. 7. Scenarios for the frequency of landslide reactivation ( $\phi$ ) obtained with multiple regression (MUL) and ECHAM 4, showing 10,50 and $90 \%$ quantiles of $\phi$. See text for explanation

\subsubsection{Analog-downscaling}

The presentation of scenarios for landslide reactivation, based on low-quality analog-downscaled precipitation scenarios, seems senseless. However, it is done merely to show that the underestimation of precipitation is amplified in $\phi$ (ECHAM 4, 1960 to 1989: 17.5\% precipitation to $81 \% \phi$ on average). This shows the importance of consistent, plausible precipitation scenarios in order to obtain consistent impact scenarios.

\subsubsection{Discussion}

A distinct change in the frequency of landslide reactivation was simulated with only 1 specific combina- tion of GCM and downscaling approach (multiple regression, ECHAM 4). This indicates that the consideration of not only different GCMs but also different downscaling methods is justified and recommended in order to better quantify the overall uncertainty in climate change impact studies.

Fig. 7 shows the scenario of landslide reactivation for multiple regression and ECHAM4 for all the time intervals. The influence of interdecadal variability of precipitation is considerable. This influence seems greater than the influence of increasing temperature, which would have resulted in a smoother decline. Temperature is important, but becomes decisive when precipitation changes are slight or become cancelled out between the seasons. Fig. 7 also shows that the 
major anomalous situations occur in the target periods 2030 to 2059 and 2040 to 2069. These were not considered in the other 2 downscaling approaches. This illustrates the importance of considering the entire scenario period instead of only 2 or 3 selected target periods in order to capture the most radical impact changes. Finally, the scenarios of different $\phi$ quantiles in Fig. 7 are further apart than the scenarios of Fig. 6. This shows that climate variability not captured by the multiple regression, or in general by the applied methods, adds a considerable amount of uncertainty to the simulated impacts. This variation is not revealed when using the other downscaling methods, but should always be considered as an important part of local climate.

\section{CONCLUSIONS}

Uncertainty in scenarios of climate change impacts is an important issue in this paper. It pertains to all stages of the climate change impact modelling approach: from errors and biases in the observations on the landslide and generalisations in the landslide model to numerous problems associated with the construction of climate scenarios. This study has shown that the use of different GCMs and downscaling methods results in a broad range of impact scenarios. There seems little point in calibrating impact models meticulously in order to improve the impact scenario with such great uncertainty remaining in the climate scenarios (obviously, this does not mean that there is no point at all in calibrating these models). Our recommendation for climate change impact model studies does not concern the use of one specific downscaling method or GCM in combination with a fully validated impact model; instead we suggest that as many uncertainties as possible be taken into account by considering different parameter settings in impact models and climate scenarios. In the meantime, while impact models are improved, GCMs and downscaling methods are improved as well.

Acknowledgements. This paper is part of the CEC Environment Research Programme on 'New technologies for landslide hazard assessment and management in Europe (NEWTECH)' (ENV4-CT96-0248). We thank Prof. Dr Hans von Storch, Dr Eduardo Zorita and Dr Hauke Heyen (GKSS Geesthacht) for providing downscaling software and for fruitful discussions; M étéofrance for providing the climatological data of Barcelonnette; Dr Erich Roeckner and Dr M onika Esch (Max-Planck-Institut für Meteorologie, Hamburg) and $\mathrm{Dr}$ David Viner (Climate Impacts LINK Project/Hadley Centre) for providing GCM data; and Dr Stefan Güss (GKSS Geesthacht) and 2 anonymous reviewers for their comments on the manuscript, which helped us make the paper clearer and more concise.

\section{LITERATURE CITED}

Airey M, Hulme M (1995) Evaluating climate model simulations of precipitation: methods, problems and performance. Prog Phys Geogr 19:427-448

Barnett T, Preisendorfer R (1987) Origins and levels of monthly and seasonal forecast skills for United States surface air temperatures determined by canonical correlation analysis. M on Weather Rev 15:1825-1850

Braam RR, Weiss EEJ, Burrough PA (1987) Spatial and temporal analysis of mass movement using dendrochronology. Catena 14:573-584

Brandsma T, Buishand TA (1997) Rainfall generator for the Rhine basin. Royal Dutch M eteorological Institute, Report 186-I, De Bilt

Buma JT (1998) Finding the most suitable slope stability model for the assessment of the impact of climate change on a landslide in South East France. Netherlands Centre for Geo-ecological Research, Report 98-3, Amsterdam

Caris J, van Asch TWJ (1991) Geophysical, geotechnical and hydrological investigations of a small landslide in the French Alps. Eng Geol 31:249-276

Craig RF (1987) Soil mechanics. Chapman \& Hall, London

Crozier M (1986) Landslides: causes, consequences and environment. Croom Helm, London

Cubasch U, von Storch H, Waszkewitz J , Zorita E (1996) Estimates of climate change in Southern Europe derived from dynamical climate model output. Clim Res 7:129-149

Dehn M, Buma J (1999) Modelling future landslide activity based on general circulation models. Geomorphology 30 : (in press)

Giorgi F, M earns LO (1991) Approaches to the simulation of regional climate change: a review. Rev Geophys 29(2): 191-216

Grotch SL, M cCracken MC (1991) The use of General CircuIation Models to predict regional climatic change. J Clim 4:286-303

Gumbel EJ (1958) Statistics of extremes. Columbia University Press, New York

Hewitson BC, Crane RG (1996) Climate downscaling: techniques and application. Clim Res 7:85-95

Heyen H, Zorita E, von Storch H (1996) Statistical downscaling of monthly mean North Atlantic air-pressure to sea level anomalies in the Baltic Sea. Tellus 48A:312-323

Houghton JT, Callander BA, Varney SK (eds) (1992) Climate change 1992. The supplementary report to the IPCC scientific assessment. Cambridge University Press, Cambridge

J ohns TC, Carnell RE, Crossley J F, Gregory J M, Mitchell J FB, Senior CA, Tett SFB, Wood RA (1997) The Second Hadley Centre coupled ocean-atmosphere GCM : model description, spinup and validation. Clim Dyn 13:103-134

Michaelsen J (1987) Cross-validation in statistical climate forecast models. J Clim Appl Meteorol 26:1589-1600

Mulder HFHM (1991) Assessment of landslide hazard. University of Utrecht, Utrecht

Roeckner E, Oberhuber J M, Bacher A, Christoph M, Kirchner I (1996) ENSO variability and atmospheric response in a global coupled atmosphere-ocean GCM. Clim Dyn 12: 737-754

Trenberth KE (1997) The use and abuse of climate models. Nature 386:131-133

Trenberth KE, Paolino DA (1980) The Northern Hemisphere sea-level pressure data set: trends, errors, and discontinuities. M on Weather Rev 108:855-872

Varnes DJ (1978) Slope movements: types and processes. In: Eckel EB (ed) Landslides analysis and control. Transporta- 
tion Research Board, Special Report 176, Washington, DC, p 11-33

von Storch H, Navarra A (eds) (1995) Analysis of climate variability. Applications of statistical techniques. Springer, Berlin

von Storch H, Zorita E, Cubasch U (1993) Downscaling of climate change estimates to regional scales an application to Iberian rainfall in winter time. J Clim 6: 1161-1171

Editorial responsibility: Hans von Storch, Geesthacht, Germany
Wigley TML, J ones PD, Briffa KR, Smith G (1990) Obtaining sub-grid-scale information from coarse-resolution general circulation model output. J Geophys Res 95:1943-1953

Zorita E, von Storch H (1998) A survey of statistical downscaling techniques. GKSS Report 97/E/20, Geesthacht

Zorita E, Hughes J P, Lettenmaier DP, von Storch H (1995) Stochastic characterization of regional circulation patterns for climate model diagnosis and estimation of local precipitation. J Clim 8:1023-1042

Submitted: November 5, 1998; Accepted: J uly 27, 1999

Proofs received from author(s): M arch 31, 2000 